\title{
Standardization construction and development trend of bridge health monitoring systems in China
}

\author{
Guang-Dong Zhou', Ting-Hua Yi ${ }^{2}$, Wen-Jie Li ${ }^{2,3}$, Ji-Wei Zhong ${ }^{4}$ and Guan-Hua Zhang ${ }^{5}$
}

\footnotetext{
* Correspondence: yth@dlut.edu.cn ${ }^{2}$ School of Civil Engineering, Dalian University of Technology, Dalian 116023, China

Full list of author information is available at the end of the article
}

\begin{abstract}
Bridge health monitoring (BHM) technology has been widely accepted as a powerful tool to assess structural performance and has moved from research to practice. Driven by the enormous demand of ensuring bridge safety, the application of BHM technology is particularly active in China and has become an emerging industry in the civil engineering community. It is a common belief among civil engineers that the development and implementation of industry standards will be of paramount importance in guiding the healthy development of $\mathrm{BHM}$ and increasing the transfer of professional knowledge and techniques to practical applications. This paper presents a comprehensive overview of the standardization construction and development trend for BHM in China. The achievements, characteristics, and challenges of China's bridge construction are first introduced. Then, the existing problems of $\mathrm{BHM}$ and the necessity of constructing the standardization system for the BHM industry are discussed. Following that, these standards published for guiding BHM system design, construction, management, and maintenance, especially sensor selection, sensor placement, sensor installation, data transmission, data storage, data processing, and early warning, are outlined. Finally, work requiring further efforts in the near future is drawn.

Keywords: Long-span bridge, Bridge health monitoring, Structural health monitoring, Standardization, Bridge safety
\end{abstract}

\section{Introduction}

Bridges are the key component of civil infrastructure for modern land transportation systems across rivers, lakes, seas, and gorges and can overcome geopolitical barriers of communication and travel. They are also an important cornerstone of economic development and a symbol of scientific development. Generally, bridges have a long service period of several decades or over one hundred years. Throughout their lifetime, they inevitably suffer from environmental corrosion, traffic loading, strong winds, temperature fluctuations, material aging or coupling effects, which lead to a decrease in their structural integrity, durability and reliability, and result in partial damage or catastrophic collapse in some extreme cases (Ou and Li 2004). As a result, how to

(c) The Author(s). 2020 Open Access This article is licensed under a Creative Commons Attribution 4.0 International License, which permits use, sharing, adaptation, distribution and reproduction in any medium or format, as long as you give appropriate credit to the original author(s) and the source, provide a link to the Creative Commons licence, and indicate if changes were made. The images or other third party material in this article are included in the article's Creative Commons licence, unless indicated otherwise in a credit line to the material. If material is not included in the article's Creative Commons licence and your intended use is not permitted by statutory regulation or exceeds the permitted use, you will need to obtain permission directly from the copyright holder. To view a copy of this licence, visit http://creativecommons.org/licenses/by/4.0/. 
identify structural damage at an early stage with the aim of ensuring the operational safety of bridges and how to predict the structural residual life with the benefit of launching cost-effective maintenance has become a crucial problem attracting extensive attention from academic researchers and administrative authorities (Ko and $\mathrm{Ni} 2005$ ).

Traditional visual inspection is usually adopted to detect structural damage and assess structural safety via nondestructive testing techniques. However, in practical applications its inherent drawbacks of experience dependence, a high time consumption, labor intensiveness, high cost, low reliability, and high subjectivity are frequently criticized. In 2000, the Federal Highway Administration of the United States found that $56 \%$ of medium-to-short-span bridges given an average condition rating by visual inspection were improperly assessed (Phares et al. 2000). By investigating the results given by 49 inspectors from 25 state agencies, routine inspections show significant variability, and the assigned condition ratings varied over a range of up to five different ratings. It is reported that only $68 \%$ of the condition ratings vary within one rating point of the average, and $95 \%$ vary within two points (Moore et al. 2001). A typical example is the Minneapolis Bridge (Interstate $35 \mathrm{~W}$ Bridge). This bridge had passed every routine visual inspection conducted annually since 1993 before it suddenly collapsed on August 1st, 2007 (Hao 2010; Nagarajaiah and Erazo 2016). In view of the abovementioned limitations of visual inspections, more reliable and accurate strategies are being pursued by researchers and engineers.

By imitating health examinations and disease diagnosis for human beings, the concept of structural health monitoring (SHM) has been put forward and immediately gained extensive interest in the civil engineering community throughout the world. Currently, SHM has become a powerful tool to track, in near real-time, the operational condition of structures during their lifetimes. Tens of thousands of SHM systems have been designed and successfully deployed on real structures (Zhou et al. 2018). Among them, the application of SHM on bridges is the most active branch. In China, the enormous demand drives the development of various commercial bridge health monitoring (BHM) systems. BHM has become an emerging industry with great potential. Currently, over 500,000 employees are engaged in the BHM industry, and over 50 million US dollars are invested in BHM every year. Unfortunately, some unfavorable facts, such as improper sensor selection, unreasonable sampling frequencies, and unstable data processing often exist in commercial BHM systems. One of the main reasons has been individuated in the lack of comprehensive standards addressing the complete BHM process. Consequently, it has become necessary to establish a complete standardization system to regulate the implementation of the BHM system and to guide the development of BHM.

In the past decade, through the cooperation of scientists from academic institutions and engineers from industry communities, intensive research has been conducted on the standardization construction of BHM in China. Many practical standards, specifications and codes have been issued for BHM system design, construction, management, and maintenance. This paper is dedicated to summarizing and reviewing recent research advances on the standardization of construction in China. The review is preceded by a brief introduction of recent achievements in bridge construction and BHM applications in China, which helps with understanding the BHM standardization system. 


\section{Recent bridge construction developments in China}

From reform and opening up to now, along with the rapid development of national science and technology, China's bridge industry has undergone three stages (i.e., learning and following in the 1980s, tracking and improving in the 1990s, and innovating and transcending since the start of the twenty-first century), and completed the transition from "follower" to "competitor," and finally to "leader." (Zhou and Zhang 2019). In this section, the achievements, characteristics, and challenges of the bridge industry in China will be presented.

\subsection{Achievements}

Due to the great efforts of Chinese researchers and engineers, a great number of technical problems in materials, design, construction and management have been solved. Highperformance materials, such as C50 and C60 concretes, Q500 steel, and $2000 \mathrm{MPa}$ steel wire, have been applied in real bridges (Zhou and Zhang 2019). Rational design methods and effective vibration control technologies have been proposed for cable-stayed bridges, suspension bridges, arch bridges, and beam-like bridges. Various construction equipment and strategies have been developed to address super-high bridge towers, super-long cables, and super-heavy girders. Advanced information technologies, including building information modeling technology, big data technology, and automatic detection technology, have been offered for bridge management. These achievements make it possible to construct complex bridges with the high performance and efficiency.

By the end of 2019, over 878,000 bridges were opened to traffic in China to fulfill the requirements of the modern land transportation system. Among them, there are many extra-long, extremely complex and world-renowned bridges with major challenges, such as the Hong Kong-Zhuhai-Macao Bridge, the Su Tong Yangtze River Highway Bridge, the Ma'anshan Yangtze River Highway Bridge, and the Hangzhou Bay Bridge. Considering the world's top 10 main span bridges of different types, the number of bridges owned by China is shown in Table 1 (Zhou and Zhang 2019). For each type of bridge, over half of them are in China. These bridges have also won over 30 outstanding international awards, including the "Major Civil Engineering Project of the Last 100 Years" awarded by the International Federation of Consulting Engineers, the "Outstanding Civil Engineering Achievement Awarded issued by the American Society of Civil Engineers, and the "Outstanding Structural Engineering Award" issued by the International Association for Bridge and Structural Engineering. All these results indicate that China's bridge engineering industry is ahead of the world and has achieved worldwide acclaim.

\subsection{Characteristics}

Compared with bridges in Europe and the United States, bridges in China have the following characteristics.

Table 1 The number of bridges owned by China among the world's top 10 main spans

\begin{tabular}{ll}
\hline Bridge type & Number \\
\hline Cable-stayed bridge & 7 \\
Suspension bridge & 6 \\
Arch bridge & 6 \\
Beam-like bridge & 6 \\
\hline
\end{tabular}


(1) Large quantities. As mentioned above, the total number of bridges in China is over 0.87 million, which surpasses every other country in the world. With the fast-growing national economy, the construction scale of bridges will still maintain a high growth rate of approximately $3 \%$ each year. It is estimated that the number of bridges in China will exceed 1.00 million by 2025.

(2) Long span. Due to the large number of rivers in China, such as the world-famous Yangtze River and Yellow River, long-span bridges used to cross wide rivers and canyons account for a high proportion of the total bridges. There are over 180 long-span bridges with main spans over $400 \mathrm{~m}$. These long-span bridges have a low stiffness and are susceptible to temperature variation, strong wind, devastating floods, and explosive blasts.

(3) Diverse loading. Due to the negligence by management, truck overloading behavior still exists. Some bridges are often loaded more than expected. Furthermore, China has a variety of climates. Bridges in southern China are vulnerable to typhoons and tornadoes beyond expectation, while bridges in northern China are vulnerable to ultra-strong blizzards and monsoons.

(4) Complicated environment. In China, different bridges may suffer from different environmental effects. In the north, extremely low temperatures in the winter, large temperature differences between day and night, and frequent freeze-thaw cycles can easily lead to the deterioration of the bridge. In the south, seawater corrosion and strong typhoons may cause the bridge to collapse instantaneously.

\subsection{Challenges}

For the reason that bridges are featured by the large number and the long span, and suffer from complex loading and unfavorable environmental effects at the same time, structural damage or collapse induced by performance degradation is reported almost every month in China. The comparison between the number of all bridges and the number of dangerous bridges in the past 5 years is displayed in Fig. 1. It can be seen from the figure that, because of the large number of bridges, the number of dangerous bridges is also very large. As the bridge construction is the main focus in China over last two decades, it is very likely that the number of dangerous bridges in China will increase dramatically in the next 10 to 20 years, which brings great challenges to the structural maintenance. As a result, it is urgent to develop effective methods for

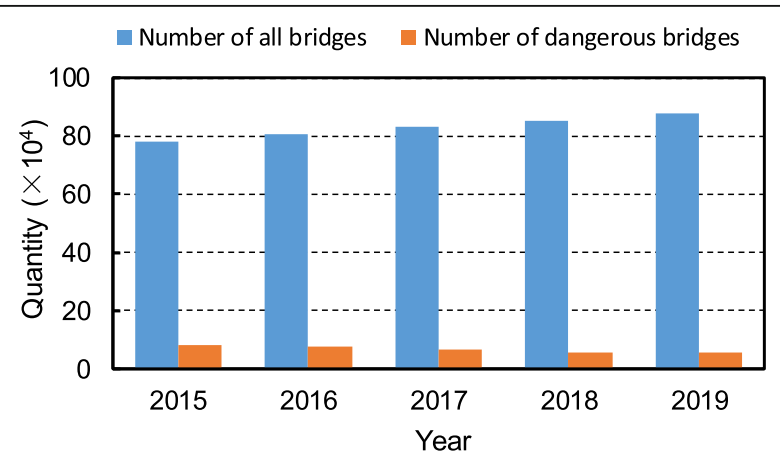

Fig. 1 Comparison between the number of all bridges and the number of dangerous bridges in China 
evaluating the bridge performance and for providing an early warning before catastrophic failure.

\section{Recent developments of BHM in China}

\subsection{Basic idea of SHM technology}

To pursue a practical and reliable strategy to assess the structural performance and ensure structural safety with a minimum traffic disturbance, the concept of SHM was proposed by mimicking the pattern of human health monitoring and immediately gained considerable attention from academics and engineering practitioners. SHM can be generally referred to as the measurement of the influential environment and the critical responses of the structure by an array of sensors to track and evaluate the symptoms of operational incidents, anomalies, and deterioration or damage indicators that may affect its operation, serviceability, safety, or reliability (Aktan et al. 2000; Li and Hao 2016). SHM technologies have the potential to replace visual inspections by fully understanding the structural static responses and dynamic behaviors. Furthermore, SHM technologies have the capability of quickly tracing the structural performance deterioration and reliably estimating the structural collapse risk. Based on this, economical maintenance strategies and retrofit patterns become possible. Currently, SHM is a popular and continuously growing research field that is increasingly becoming a focus in the civil engineering community.

A typical SHM system generally consists of four major components: the sensor subsystem, the data acquisition and transmission subsystem, the data management subsystem, and the condition evaluation subsystem, as shown in Fig. 2. The sensor subsystem and the data acquisition and transmission subsystem are usually located at the structural site, while the data management subsystem and the condition evaluation subsystem are often placed inside the monitoring center located away from the structural site. The sensor subsystem is responsible for collecting data associated with the influential environment and critical responses. The data acquisition and transmission subsystem interrogates various types of signals and transmits them to the data management subsystem. The data management subsystem refers to data storage, reading data, data preprocessing, data display, and data inquiry. The condition evaluation subsystem integrates a large number of numerical signal processing algorithms and structural condition evolution methods to extract the damage indicators (Zhou et al. 2017).

According to the pattern of data collection, SHM systems can be divided into continuous monitoring systems, routine monitoring systems, and trigger-based monitoring systems. Continuous monitoring systems, which operate $24 \mathrm{~h}$ a day, 7 days a week, have

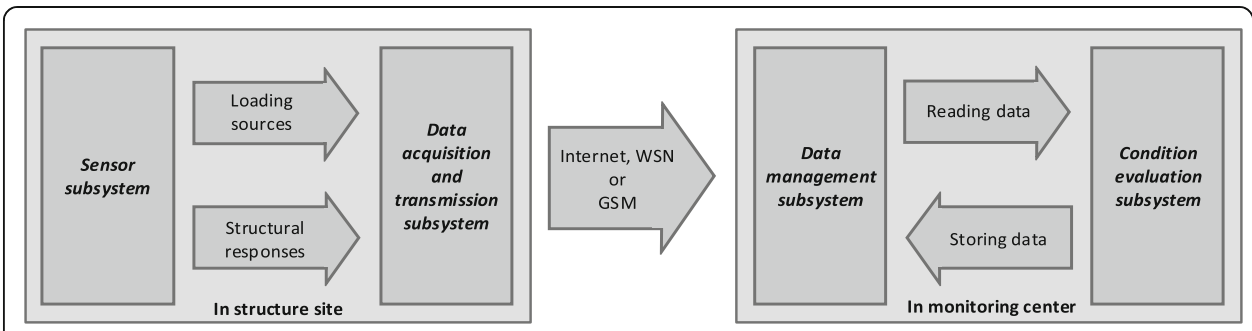

Fig. 2 Subsystems of the SHM system 
the capability of capturing all information about the environment, loads and responses. The routine monitoring systems monitor the structure according to a schedule, which may be $1 \mathrm{~h}$ a day, 1 day a week, or 1 day a month. Trigger-based monitoring systems begin to work when some preset indicators exceed the threshold. This pattern has the highest efficiency. According to the pattern of data transmission, SHM systems can be classified as wired monitoring systems and wireless monitoring systems. Wired monitoring systems adopt cables to provide a solid data transmission path, while wireless monitoring systems use wireless sensor networks (WSNs) to transfer information from sensor to sensor and from sensor to central data repository. These are considered to be an attractive alternative to wired monitoring systems (Zhou and Yi 2013).

From a comprehensive perspective, the significance of SHM systems is generally envisaged, but is not limited to: (1) identifying anomalies in external loading and structural responses and possible damages prior to costly repairs or even catastrophic collapses; (2) launching a structural performance evaluation immediately after disasters and extreme events, such as earthquakes and explosions; (3) reconsidering the reliability and rationality of design assumptions and models with the potential benefit of improving design methods and specifications; (4) providing instruction for maintenance by replacing scheduled and periodic inspections with optimal performance-based prognostic and preventative repairs; (5) providing evidence for evaluating the effectiveness of maintenance, retrofit and repair works; and (6) acquiring a vast amount of in situ data for leading edge research in structural engineering, such as vibration-control designs, new material applications and novel structural systems (Ko and Ni 2005; Li et al. 2016).

To achieve the above goals, SHM research requires multidisciplinary cooperation and involves technical issues, data issues, and scientific issues. Technical issues are concerned with various technical problems encountered when finishing an effective SHM system, including sensor design, network organization, cloud platform construction, system integration, etc. Data issues relate to the processing of collected data and the extraction of indices describing structural conditions, such as data modeling, big data analysis, and artificial intelligence. Scientific issues refer to the application of monitoring results to interpret structural behaviors, such as the validation of design assumptions, the exploration and verification of damage evolution mechanisms, the assessment and early warning of structural safety, the prediction of residual life, and the development of life-cycle design methods.

\subsection{Typical BHM applications}

Compared with other civil infrastructures (i.e., high-rise buildings, long-span stadiums, tunnels, and high dams), long-span bridges with a high flexibility are more easily damaged by a dynamic load, fatigue load and material aging. As a result, the application of SHM technologies on bridges is the most active branch in the SHM community in China, which makes BHM a widely known term.

Hence, a variety of advanced techniques and methods have been developed for BHM. For example, various sensors based on resistance, piezoelectric ceramic and fiber Bragg grating have been devised and tested on real bridges; many signal processing approaches originating from the Fourier transform, the wavelet transform and the Hilbert Huang transform have been proposed and applied to identify modal parameters and 
performance indices, and multivariate statistical models, Bayesian statistical models and extreme value analysis models have been developed to describe the statistical characteristics of load and response (Xu 2018; Lam et al. 2018). Diversiform linear, nonlinear and learning models are used to describe the relationships between the structural inputs and outputs and to predict the structural behavior in the future (Azimi et al. 2020). These technologies and methods make BHM more effective, reliable, low-cost and intelligent. As a result, over 165 bridges whose main spans exceed $300 \mathrm{~m}$ in China are equipped with long-term BHM systems for varying motives. Some selected cases where BHM systems have been employed to evaluate structural performance during their lifetime are listed in Table 2 (Ko and Ni 2005; Huang et al. 2003; Li et al. 2003; Zhen et al. 2018).

\subsection{Existing problems}

Great achievements have been made in the design and application of BHM systems. However, there are still wide gaps between the implementation of BHM systems and the evaluation of bridge performance. Many application issues need to be further addressed.

(1) The purpose of BHM systems is often not fully understood by designers. Health monitoring systems designed by different designers are quite different, even for bridges with similar structural features, as shown in Table 2. Consequently, the performances of health monitoring systems show great differences.

(2) The hardware selection may be unreasonable. Instances are insufficient lowfrequency resolution of acceleration sensors, lack of long-term stability of the strain sensors, and cables without a signal shielding ability. These defects may reduce the fidelity of data and even cause signal contamination.

(3) Sensors are often placed according to experience, without full consideration of the structural characteristics, which may result in insufficient data or information redundancy. Limited sensor resources cannot be fully utilized.

(4) Sensors are not properly installed or protected, especially for sensors placed on structural surfaces. As a result, rain erosion may dramatically shorten the sensor lifetime, and electromagnetic interference may reduce the fidelity of the signal.

(5) Sampling frequency is set subjectively. In some BHM systems, the sampling frequency is high, which leads to huge amount of data and low efficiency of data processing. In other BHM systems, the sampling frequency is too low to capture the dynamic characteristics and critical responses of the structure.

(6) Data format is not uniform. Some BHM systems store data by sensor number, while some BHM systems store data by date. Some BHM systems store a day's data as a file, while others store an hour's data as a file. This makes data sharing extremely difficult.

(7) Early warning policies are empirical. In some BHM systems, the warning threshold is too strict, which leads to frequent alarms of normal events, while in other systems the early warning threshold is too loose, which results in no alarm for abnormal events.

In view of the above dilemma, subjective, empirical and arbitrary behaviors often govern the design, installation and operation of BHM systems, which may reduce system 


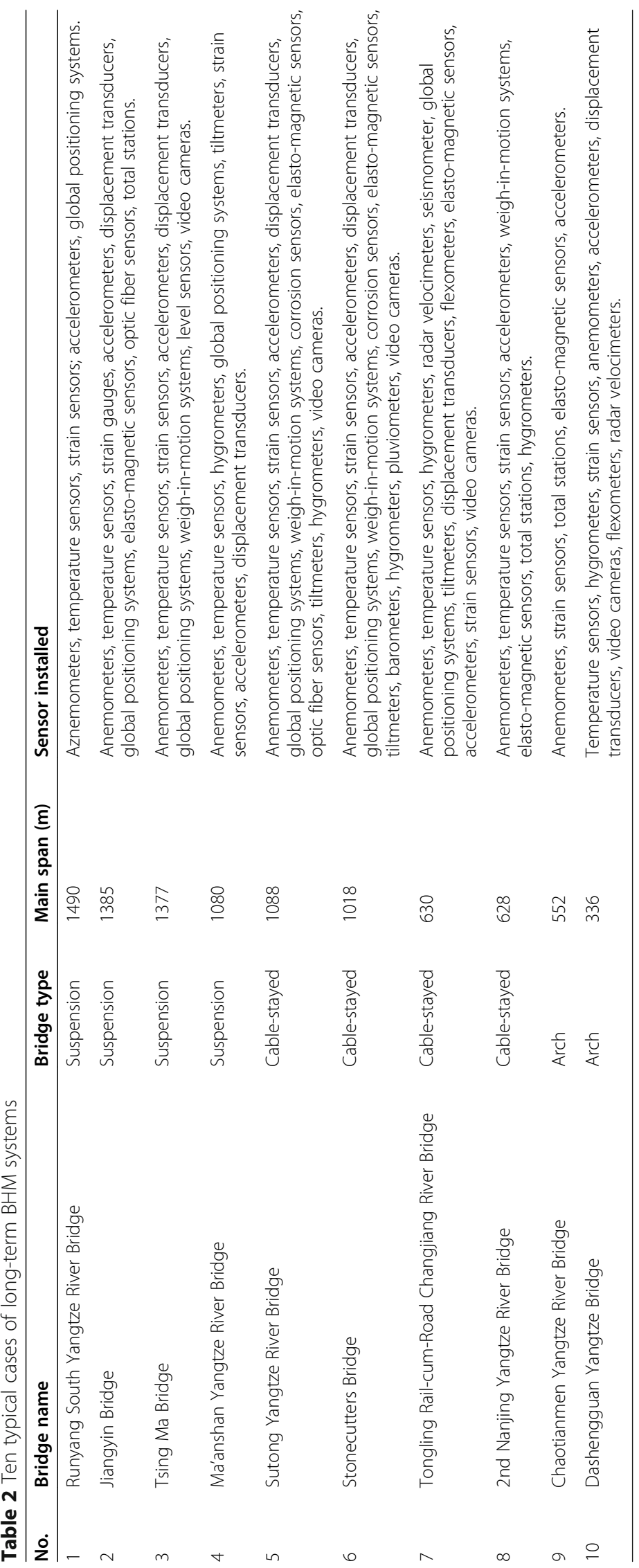


performance and make monitoring invalid. Some bridge owners even question the feasibility of BHM systems in ensuring bridge safety. As a result, the development of the BHM industry has slowed greatly. Taking a close look at this situation, it can be determined that the primary reason is a lack of a complete standardization system to guide the design, installation and operation of BHM systems. From this point of view, establishing BHM standards to lead the application of BHM technologies is significant.

\section{Recent development of standardization construction for the BHM industry in China}

\subsection{Overview of the standardization system}

Differing from the standardization system in the USA, which is composed of the model code, the consensus standard, and the resource document, the standardization system in China consists of standard, specification, and code. The standard is a document that specifies common and reusable rules, guidelines, or characteristics for an activity or its results in order to achieve the best order within a certain range. The specification is a series of regulations on design, construction, manufacturing, inspection and other technical matters in industrial and agricultural production and engineering construction. The code is a unified regulation of technical requirements and implementation procedures for operation, installation, identification, safety, and management. Standard, specification, and code are different forms of standards, so they are uniformly referred to as standards.

According to the authority of standards, standards can be divided into four levels, including national standards, professional standards, provincial standards, and company standards, as demonstrated in Fig. 3. Company standards are valid within the company; provincial standards are valid within the province, which may span several companies or industries; professional standards are only valid in a specific industry, which may cover several provinces and companies; and national standards are applicable throughout the country. National standards, which have the strongest power, are recommended and supervised by the Government of China. Other standards cannot conflict with

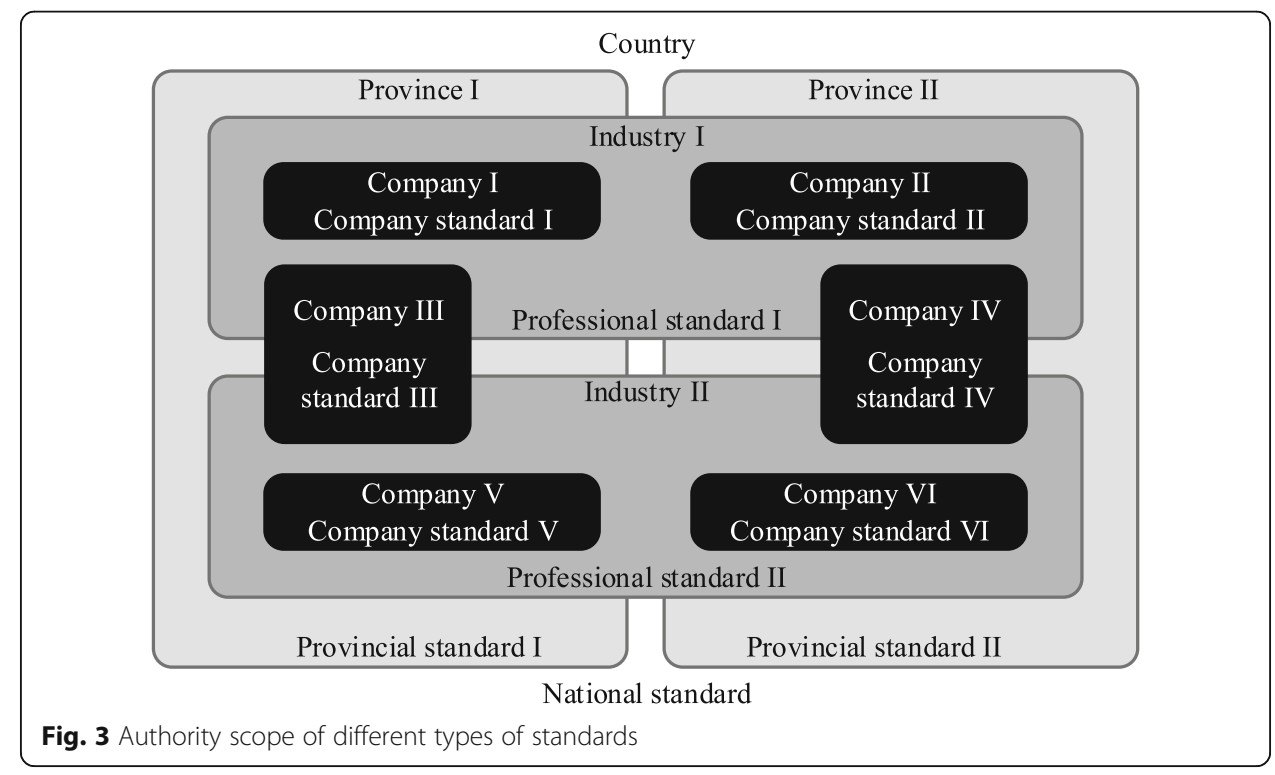


national standards. Once a national standard is issued, these overlaps in professional standards, provincial standards or company standards will be abolished accordingly. National standards are the main body of the standardization system. Professional standards refer to the technical requirements that are not recommended in national standards but need to be unified in a certain industry community. Professional standards are supplements to the national standard. Provincial standards, which are supplements to the national standard and the professional standard, meet the local natural conditions, customs and other special technical requirements. Company standards, which rank the lowest among all standards, are standards unifying the technical requirements, management requirements and work requirements within the company.

\subsection{Significance of BHM standardization}

As mentioned above, unreasonable hardware selection, improper sensor installation, subjective data collection, and arbitrary early warning thresholds exist in many commercial BHM systems. As a result, these cases, such as the failure of a large number of sensors within a few months, the collapse of the entire system in less than 2 years, more than half of the total monitoring data being invalid, the forced shutdown of the early warning system due to invalid data, etc., have been reported. The operation performance of BHM systems is far from expected. Standardization of the BHM industry, which refers to establishing a complete standardization system to guide all bridge monitoring behaviors, is a necessary way to narrow the gap between the expected and actual performance of BHM systems.

In addition to regulating the design, installation, operation and maintenance of BHM systems and ensuring system performance, the potential benefits of standardization include: (1) leading the rapid and healthy development of the BHM industry and avoiding subjective and unreasonable behaviors to interfere with the BHM industry; (2) encouraging these authorities who question the effectiveness of BHM to put aside their doubts and apply BHM technologies in ensuring bridge safety; (3) making the transition of novel sensors, data processing algorithms, and damage identification techniques from research to commercial application; (4) helping to determine the shortcomings of the existing technology and then promoting further research on BHM technologies; and (5) providing reliable data that can describe the real operational behavior of bridges to improve structural design methods, specifications, models and theories.

\subsection{Framework of the BHM standardization system}

Establishing a complete standardization system for the BHM industry is not easy. First, the implementation of the BHM system is composed of the design, installation, operation and maintenance, involving the adoption of technologies developed in different disciplines, such as sensors, sensor networks, communication, signal processing, and information management, to the bridge engineering community. Multidisciplinary cooperation is essential and challenging. Then, different types of bridges (i.e., beam-like bridges, arch bridges, cable-stayed bridges, suspension bridges) have different static and dynamic behaviors, so the monitoring requirements associated with sensor selection, network configuration, sampling frequency and management policies are varied. Refining the generality of BHM statements is complicated. Third, a large amount of 
hardware based on a variety of measurement theories is available for BHM. Since each of these pieces of hardware has its own pros and cons, it is difficult to give a general and reasonable rule for selection. Last but not least, almost all signal processing methods and performance evaluation methods have limitations. A method that is suitable for detecting one type of damage may not be useful for detecting other types of damage. Providing general suggestions for method selection presents great challenges.

To cope with the parameter diversity and process complexity of BHM, the BHM standardization system could be completed from various approaches, as listed in Table 3. According to the implementation process of the BHM system, standardization for the BHM industry could be achieved by guiding the implementation processes of the design, construction, acceptance, maintenance and management. By standardizing the monitoring of different types of bridges, the BHM standardization system could be finished by establishing monitoring standards for beam-like bridges, arch bridges, cable-stayed bridges, suspension bridges, and bridge groups, or for pedestrian bridges, highway bridges, railway bridges, rail-cum-road bridges, and bridge groups. Through standardizing various monitoring technologies, the BHM standardization system could include standards for piezoelectric technology, optical fiber technology, video technology, resistance technology, global positioning system technology, etc. Moreover, the BHM standardization system could consist of standards for various application functions, such as static data collection, dynamic data collection, modal parameter identification, early warning thresholds, and fatigue assessment.

\subsection{BHM standards}

Fortunately, the importance of BHM standardization has been acknowledged by researchers and end-users, and much effort has been made in this topic. At present, many standards that could be used for guiding bridge monitoring have been issued in China. These standards could be roughly classified into two categories. The first category of standards is applicable to all types of civil infrastructures. The second category of standards is specific to certain types of structures, such as high-rise buildings, long-span bridges, high dams, high towers, etc. In this section, both versatile SHM standards and specific BHM standards are introduced because all of them could be employed to guide

Table 3 Framework of the BHM standardization system

\begin{tabular}{ll}
\hline Approach & Component \\
\hline $\begin{array}{l}\text { By standardizing implementation } \\
\text { processes of BHM systems }\end{array}$ & Design, construction, acceptance, maintenance, management. \\
$\begin{array}{l}\text { By standardizing the monitoring of } \\
\text { different types of bridges }\end{array}$ & $\begin{array}{l}\text { Beam-like bridges, arch bridges, cable-stayed bridges, suspension } \\
\text { bridges, bridge groups. } \\
\text { Or pedestrian bridges, highway bridges, railway bridges, and } \\
\text { rail-cum-road bridges, bridge groups. }\end{array}$ \\
$\begin{array}{ll}\text { By standardizing monitoring } \\
\text { technologies used for BHM }\end{array}$ & $\begin{array}{l}\text { Pystem technology, radar technology, video technology, resistance } \\
\text { technology, capacitance technology, weight-in-motion technology, } \\
\text { wind monitoring technology, elasto-magnetic technology, connected } \\
\text { pipe technology, etc. } \\
\text { By standardizing application functions } \\
\text { in BHM systems }\end{array} \quad \begin{array}{l}\text { Static data collection, dynamic data collection, statistical analysis, } \\
\text { assessment, etc. }\end{array}$ \\
\hline
\end{tabular}


Table 4 SHM standards in China

\begin{tabular}{|c|c|c|c|c|c|}
\hline No. & Name & Types & Level & $\begin{array}{l}\text { Serial } \\
\text { number }\end{array}$ & Issue time \\
\hline 1 & $\begin{array}{l}\text { Basic Terms on Safety Monitoring for Engineering } \\
\text { Disaster Prevention }\end{array}$ & Standard & National & & To be issued \\
\hline 2 & $\begin{array}{l}\text { Design Standard for Structural Health Monitoring } \\
\text { Systems }\end{array}$ & Standard & Professional & CECS 333 & 2012 \\
\hline 3 & $\begin{array}{l}\text { Standard for Operational Maintenance and } \\
\text { Management of Structural Health Monitoring Systems }\end{array}$ & Standard & Professional & T/CECS 652 & 2019 \\
\hline 4 & $\begin{array}{l}\text { Standard for Construction and Acceptance of } \\
\text { Structural Health Monitoring Systems }\end{array}$ & Standard & Professional & - & To be issued \\
\hline 5 & $\begin{array}{l}\text { Standard of Massive Data Processing for Structural } \\
\text { Health Monitoring }\end{array}$ & Standard & Professional & - & To be issued \\
\hline
\end{tabular}

the implementation of bridge monitoring. The basic information of these standards is listed in Tables 4 and 5. It is worth noting that since the company standard is only valid within the company and difficult to obtain from open channels, these company standards relating to BHM are not listed here. In addition, due to the limited knowledge of the authors, omission and prejudice are inevitable.

\subsubsection{Brief description of SHM standards in China}

"Basic Terms on Safety Monitoring for Engineering Disaster Prevention" provides the basic terms and their definitions regarding engineering disasters, basic methods of safety monitoring, sensor packages, optimal sensor placement, data acquisition and transmission, data storage and management, operation and maintenance of monitoring

Table 5 BHM standards in China

\begin{tabular}{|c|c|c|c|c|c|}
\hline No. & Name & Types & Level & Serial number & Issue time \\
\hline 1 & $\begin{array}{l}\text { Structural Health Monitoring System } \\
\text { Technical Specification for Bridge } \\
\text { of Tianjin }\end{array}$ & Standard & Provincial & DB/T29-208 & 2011 \\
\hline 2 & $\begin{array}{l}\text { Technical Code for Monitoring of Building } \\
\text { and Bridge Structures }\end{array}$ & Code & National & GB50982 & 2014 \\
\hline 3 & $\begin{array}{l}\text { Technical Specification for Structural Safety } \\
\text { Monitoring Systems of Highway Bridges }\end{array}$ & Specification & Professional & JT/T1037 & 2016 \\
\hline 4 & $\begin{array}{l}\text { Specifications for Structural Health } \\
\text { Monitoring System Design, Construction } \\
\text { and Maintenance of Bridges and Tunnels } \\
\text { based on Fiber Optic Sensing }\end{array}$ & Specification & Provincial & DB32/T 2880 & 2016 \\
\hline 5 & $\begin{array}{l}\text { Guidance for Design and Maintenance } \\
\text { of Health Monitoring System for } \\
\text { Concrete Bridge Structures }\end{array}$ & Code & Provincial & DB13/T 2548 & 2017 \\
\hline 6 & $\begin{array}{l}\text { Standard for Construction and Acceptance } \\
\text { of Structural Health Monitoring Systems } \\
\text { for Bridges }\end{array}$ & Standard & Provincial & DBJ50/T-304 & 2018 \\
\hline 7 & $\begin{array}{l}\text { Early Warning Threshold Standard for } \\
\text { Structural Health Monitoring System of } \\
\text { Long-Span Bridge }\end{array}$ & Standard & Professional & T/CECS 529 & 2018 \\
\hline 8 & $\begin{array}{l}\text { Design Code for Bridge Structural Health } \\
\text { Monitoring System }\end{array}$ & Code & Provincial & DB32/T 3562 & 2019 \\
\hline 9 & $\begin{array}{l}\text { Technical Regulation on Sensor Selection } \\
\text { and Placement for Bridge Health Monitoring }\end{array}$ & Code & Professional & - & To be issued \\
\hline
\end{tabular}


system, establishment and modification of numerical models, feature extraction and performance evaluation. These definitions are applicable to engineering practice and scientific research and help with understanding the operation and behavior of structural monitoring, especially for these confusing statements. This standard is also the basic criterion for publishing other structural monitoring standards.

The "Design Standard for Structural Health Monitoring System (CECS 333: 2012)" was the first professional standard in the field of SHM in China and was approved by the China Association for Engineering Construction Standardization (CECS). The standard consists of seven chapters, two annexes, and explanations, featured by carefully guiding the design of the SHM subsystems, including the sensor subsystem, data acquisition and processing subsystem, data communication and transmission subsystem, and damage identification and safety assessment subsystem. The critical criteria for data collection, transmission and processing are presented, which help in selecting hardware and integrating software in the SHM system. These technical specifications are the basis for designing comprehensive SHM systems and have an essential reference value for the development of follow-up SHM standards.

Like the structural system, which requires routine maintenance and reasonable management, the SHM system also requires periodic inspections and retrofitting to maintain its performance. To provide professional guidelines for the maintenance and management of the SHM system, "Standard for Operational Maintenance and Management of Structural Health Monitoring Systems (T/CECS 652-2019)" has been published. In this standard, the maintenance period of software and hardware, the routine management of operational software and hardware, and equipment inspection and maintenance, including sensors, data acquisition devices, data transmission devices, data storage devices, and data display devices, are specified. The procedure of routine management and the record and handling forms of abnormal events are provided as appendices. In accordance with T/CECS 652-2019, the durability of SHM systems is expected to be assured.

The "Standard for Construction and Acceptance of Structural Health Monitoring Systems" addresses the criterion of SHM system construction and acceptance, and has been finished. To extricate from the predicament that the reliability and performance of the SHM system cannot be ensured because most construction workers lack professional SHM knowledge, the first part of the standard lists detailed requirements and suggestions of system preconstruction preparation, sensor installation, cable laying, installation of data transmission equipment, installation of a data acquisition substation, and configuration of the monitoring center. The second part of the standard provides criteria for hardware and software acceptance. The last part of the standard specifies information of the SHM system itself, which should be compiled and archived. With the help of this standard, the gap between the design expectation and the real performance of the SHM systems is bridged.

The core task of SHM is to properly process the data collected by the SHM system and extract the parameters describing the structural performance. However, the majority of SHM standards cannot offer detailed specifications to clarify how to process monitoring data because of the complications of this work. "Standard of Massive Data Processing for Structural Health Monitoring" has been completed to tackle this challenge. This standard puts forward rich suggestions for monitoring data processing, such 
as data storage, data compression, data decompression, data interchange, data denoising, data filtering, data repairing, statistical analysis, modal parameter identification, damage identification, fatigue assessment, condition assessment, and outcome expression, covering the majority of practical data processing methods. This standard makes the performance evaluation module in the health monitoring system more effective.

\subsubsection{Brief description of BHM standards in China}

The "Structural Health Monitoring System Technical Specification for Bridge of Tianjin (DB/T29-208-2011)" was the first BHM standard issued in China. This standard is a preliminary attempt to develop Chinese BHM standards and consists of seven parts: the system framework, the sensory system, the data acquisition and transmission system, the structural health evaluation system, the structural health data management system, system inspection, and system maintenance. Although specific technical requirements for hardware, such as the ultrasonic anemometer, the mechanical anemometer, the strain sensor, the accelerometer, the displacement sensor, the temperature sensor, the fiber Bragg grating signal demodulator, the data acquisition device, the data cable, etc., are provided for designing BHM systems, they are limited by the technical advances and research outcomes of at that time, so the rationality of some details needs to be further verified.

"Technical Code for Monitoring of Building and Bridge Structures (GB50982-2014)" is an exclusive national SHM code with mandatory requirements in China and consists of eight chapters, two appendixes and explanations. The main content includes basic requirements, monitoring methods for environmental temperature, humidity and structural responses, and specifications for various types of structures (i.e., high-rise buildings and structures, long-span spatial structures, bridge structures, seismically isolated structures, and crossing construction) involving sensor arrangement, monitoring parameter selections and condition assessments for construction and post-construction, as well as technical requirements. This code provides the primary framework of structural monitoring. The outstanding characteristics of this code is that detailed monitoring requirements for various structures during both construction and post-construction stages are put forward, and parameters that need to be measured during construction and post-construction stages are clarified.

"Technical Specification for Structural Safety Monitoring Systems of Highway Bridges (JT/T1037-2016)" was issued by the Ministry of Transportation of the People's Republic of China in 2016. The main content of the specification is composed of six parts (i.e., the framework of the monitoring system, structural parameter and sensor selection, sensor requirements, requirements of data collection, transmission and management, safety evaluation requirements, and requirements of system integration and terminal interface). This specification divides structural parameters into three groups, including load and environment, structural global responses, and structural local responses. It also addresses which parameters should be monitored, how to monitor these parameters, what type of sensors should be used, and how to collect and process data, which offers a large number of instructions for BHM system practitioners.

"Specifications for Structural Health Monitoring System Design, Construction and Maintenance of Bridges and Tunnels based on Fiber Optic Sensing (DB32/T 2880- 
2016)" is specially issued for optical fiber monitoring technology and is applicable in bridge and tunnel monitoring because optical fiber monitoring technology is a very potential technology that has been widely used in bridge and tunnel monitoring. These details involving the parameter requirements of optical fiber sensors, the optimal placement of optical fiber sensors, the installation of optical fiber sensors, data collection, data processing, data transmission, data storage, structural damage identification, condition assessment, and residual life prediction are specified. The publication of this specification provides an important reference for the development of various technical specifications.

The mechanical characteristics and durability of concrete bridges are quite different from those of steel bridges and steel-concrete composite bridges. As a consequence, the monitoring parameters and strategies of concrete bridges also have their own features. For example, the strain in concrete can be effectively monitored. The code entitled "Guidance for Design and Maintenance of Health Monitoring System for Concrete Bridge Structures (DB13/T 2548-2017)" has been published for concrete bridge monitoring in Hebei Province. In this guide, these indices indicating durability, including deformation, cracks, strain, temperature, humidity, and reinforcement corrosion, are emphasized. A variety of technical requirements are listed for the selection of monitoring hardware. This guidance provides rich information for the monitoring of concrete bridges.

"Standard for Construction and Acceptance of Structural Health Monitoring Systems for bridges (DBJ50/T-304-2018)" is a provincial standard issued by the government of Chongqing. Being different from other SHM/BHM standards, this provincial standard focuses on the installation and acceptance of BHM systems, which is frequently overlooked but a crucial step in ensuring the effectiveness of BHM systems. The main content consists of two parts: (1) the construction requirements of sensors (i.e., weigh-inmotion sensors, wind speed and direction sensors, ground motion sensors, temperature and humidity sensors, displacement sensors, strain sensors, acceleration sensors, anchorage meters, and inclinometers), the wiring system, the measurement station, the computer room, software testing and deployment, system debugging, and system trail running; and (2) the acceptance criteria of all components of the BHM system. This standard clarifies the importance and requirements of BHM system construction.

One of the main challenges for completing an effective BHM system is the selection of proper thresholds to realize structural anomaly warning. The "Early Warning Threshold Standard for Structural Health Monitoring System of Long-Span Bridge (T/ CECS 529-2018)" was developed to address this challenge. Through the cooperation of scholars and engineers, the early warning thresholds of natural loads, man-made loads, and static responses of each bridge component (i.e., towers, cables, girders, piers, anchorages, foundations, expansion joints and supports), the dynamic responses of each bridge component, and the entire bridge performance are given. For each index, there are four levels of early warning thresholds that indicate extremely dangerous, very dangerous, dangerous, and abnormal cases, which are shown on the monitoring screen in red, orange, yellow and blue, respectively. This standard narrows the gap between the research of damage identification and the warning of damage in real structures. 
The "Design Code for Bridge Structural Health Monitoring System (DB32/T 3562 2019)" is a provincial standard and is only valid in Jiangsu Province. As a supplement to the national standard GB50982-2014 and the professional standard JT/T1037-2016, the main content of this provincial standard includes general requirements, the design requirements of the sensor subsystem, the design requirements of the data acquisition and transmission subsystem, the design requirements of the data storage and processing subsystem, and the design requirements of the early warning and condition evaluation subsystem. The attention limited to BHM system design is one shortcoming of this report, and the implementation of the BHM system should be more elaborated.

"Technical Regulation on Sensor Selection and Placement for Bridge Health Monitoring" is a code especially dealing with how to select and place monitoring sensors. This code will be issued soon and is composed of four parts. The first part offers the basic requirements for sensor selection and placement. The second part outlines the requirements of technical parameters and the locations of sensors used for monitoring vehicle loads, wind loads, ground motion, environmental temperature, environmental humidity, and corrosive media. The third part specifies how to monitor the girders, arches, towers, main cables, stay cables, suspenders, anchorages, expansion joints, supports, piers, abutments and foundation for beam-like bridges, arch bridges, cable-stayed bridges, and suspension bridges, including sensor selection, sensor placement, and sampling frequency. The last part covers the sensor selection and placement for durability monitoring of concrete components and steel components. According to this code, sensors could be appropriately selected and placed, even for practitioners who lack professional BHM knowledge.

It should be noted that selecting a proper standard to guide the design and operation of a specific BHM is an important issue for the implementation of BHM standards. In general, the national standard must be adopted. There are no unified guidelines indicating how to deal with the conflicts among professional standards, provincial standards, and company standards. This is also significant work that needs to be done during constructing bridge health monitoring systems in China.

\section{Conclusions}

This paper presented an overview of bridge construction, BHM application, and BHM standardization construction in China. Emphases were laid on new advances in BHM standards. Various standards published for the BHM industry in China were outlined. However, the work of BHM standardization construction is far from complete. At the very least, the following aspects require contributions from scholars of different disciplines.

(1) In a health monitoring system, hardware is just the skeleton, while software is the brain to ensure the operation of the system. Most existing BHM standards focus on hardware selection and installation. How to design software for reliable condition assessment should be guided. Therefore, the BHM standardization system needs to be further perfected. In particular, a great number of signal processing and damage identification algorithms have been proposed in the literature, but to date, only a few of them have been recommended by BHM standards. Further work should therefore address the capability and limitations of 
these algorithms and the selection of the most appropriate algorithms in real practice.

(2) Propagation and promotion are essential work after the publication of standards. BHM participants, especially bridge owners and administrators, cannot obtain the published information of new BHM standards in time. As a consequence, these specifications in new BHM standards are mothballed, which may leave defects in the BHM system that are difficult to repair. For example, embedded sensors may be improperly selected. Therefore, it is necessary to propagate BHM standards to all participants in the BHM industry. Furthermore, the underlying reason for raising such requirements or giving such suggestions should be clearly explained so that the standard can be reasonably executed.

(3) It has been demonstrated that, although the BHM system increases the initial cost of a bridge, the failure cost and the additional costs are decreased, which would reduce the total life-cycle cost, including construction cost and maintenance cost. It is possible that a smaller safety coefficient could be used if a BHM system serves as a basic tool for ensuring bridge safety during the construction stage and the service life. However, a large number of sensors and cables often affect the installation and use of the bridge's electrical equipment, such as lighting wires and camera cables. Therefore, one critical point of the new generation of BHM standards is to realize the collaborative design of structural systems and monitoring systems by using building information modeling technology and the intelligent construction technology.

\section{Abbreviations}

SHM: Structural health monitoring; BHM: Bridge health monitoring

Acknowledgements

Not applicable.

\section{Authors' contributions}

Guang-Dong Zhou, Wen-Jie Li, and Guan-Hua Zhang collected the information about BHM standards in China and were major contributors in writing the manuscript. Ting-Hua Yi and Ji-Wei Zhong established the framework of the manuscript and were major contributors in writing the manuscript. All authors read and approved the final manuscript.

Funding

This research work was jointly supported by the National Key Research and Development Program of China (Grant No. 2019YFC1511000), the National Natural Science Foundation of China (Grant Nos. 51678218, 51625802, 51978128), and the Science Fund for Excellent Young Scholars of Jiangsu Province (Grant No. BK20170097).

\section{Availability of data and materials}

The datasets used and analyzed during the current study are available from the corresponding author on reasonable request.

Competing interests

The authors declare that they have no competing interests.

\section{Author details}

${ }^{1}$ College of Civil and Transportation Engineering, Hohai University, Nanjing 210098, China. ${ }^{2}$ School of Civil Engineering, Dalian University of Technology, Dalian 116023, China. ${ }^{3}$ China Communications Construction Company Ltd., Beijing 100088, China. ${ }^{4}$ State Key Laboratory for Health and Safety of Bridge Structures, China Railway Bridge Science Research Institute Ltd., Wuhan 430034, China. ${ }^{5}$ Liaoning Provincial Transportation Planning and Design Institute Co., Ltd., Shenyang 110166, China. 
Received: 11 October 2020 Accepted: 9 November 2020

Published online: 23 November 2020

\section{References}

Aktan AE, Catbas FN, Grimmelsman KA, Tsikos CJ (2000) Issues in infrastructure health monitoring for management. J Eng Mech 126(7):711-724

Azimi M, Eslamlou AD, Pekcan G (2020) Data-driven structural health monitoring and damage detection through deep learning: state-of-the-art review. Sensors 20(10):2778. https://doi.org/10.3390/s20102778

Hao S (2010) I-35W bridge collapse. J Bridg Eng 15(5):608-614

Huang T, Zheng YH, Wu HL, Wang CJ (2003) Structural safety monitoring system for the second Nanjing Yangtze River bridge. J Hohai Univ 31(4):411-416 [in Chinese]

Ko JM, Ni YQ (2005) Technology developments in structural health monitoring of large-scale bridges. Eng Struct 27(12):17151725

Lam HF, Yang JH, Au SK (2018) Markov chain Monte Carlo-based Bayesian method for structural model updating and damage detection. Struct Control Health Monit 25(4):e2140

Li AQ, Miao CQ, Zhao L (2003) The health monitoring system for the Runyang Yangtze River bridge. In: Wu ZS, Abe M (eds) 1st international conference on structural health monitoring and intelligent infrastructure, Tokyo, Japan, 2003

Li HN, Ren L, Jia ZG, Yi TH, Li DS (2016) State-of-the-art in structural health monitoring of large and complex civil infrastructures. J Civ Struct Health 6(1):3-16

Li J, Hao H (2016) A review of recent research advances on structural health monitoring in Western Australia. Struct Monit Maintenance 3(1):33-49

Moore M, Phares BM, Graybeal B, Rolander D, Washer G, Wiss J (2001) Reliability of visual inspection for highway bridges, volume I: final report (no. FHWA-RD-01-020). Washington, D.C: U.S Department of Transportation, Federal Highway Administration, turner-Fairbank highway research center

Nagarajaiah S, Erazo K (2016) Structural monitoring and identification of civil infrastructure in the United States. Struct Monit Maintenance 3(1):51-69

Ou J, Li H (2004) Recent advances of structural health monitoring in mainland China. In: Paper presented at the 3rd international conference on structural health monitoring of intelligent infrastructure, Vancouver, Canada, 13-16 November, 2007

Phares BM, Rolander DD, Graybeal BA, Washer GA (2000) Studying the reliability of bridge inspection. Public Roads 64(3):1519

Xu YL (2018) Making good use of structural health monitoring systems of long-span cable-supported bridges. J Civ Struct Health 8(3):477-497

Zhen W, Zhen G, Li Q, Zhang Y (2018) Research on structural health monitoring system of Ma'anshan Yangtze River highway bridge. Highway Traffic Technol (Application Technology Edition) 5:233-235 (in Chinese)

Zhou GD, Yi TH (2013) Recent developments on wireless sensor networks technology for bridge health monitoring. Math Problems Eng 2013:947867

Zhou GD, Yi TH, Chen B (2017) Innovative design of a health monitoring system and its implementation in a complicated long-span arch bridge. J Aerospace Eng 30(2):B4016006

Zhou GD, Yi TH, Chen B, Chen X (2018) Modeling deformation induced by thermal loading using long-term bridge monitoring data. J Perform Constr Facil 32(3):04018011

Zhou X, Zhang X (2019) Thoughts on the development of bridge technology in China. Engineering 5(6):1120-1130

\section{Publisher's Note}

Springer Nature remains neutral with regard to jurisdictional claims in published maps and institutional affiliations.

\section{Submit your manuscript to a SpringerOpen ${ }^{\circ}$ journal and benefit from:}

- Convenient online submission

- Rigorous peer review

- Open access: articles freely available online

High visibility within the field

- Retaining the copyright to your article

Submit your next manuscript at $\mathbf{s p r i n g e r o p e n . c o m ~}$ 